\title{
Enhancement of zinc oxide-mediated solar light decoloration of Acid Yellow 99 dye by addition of $\beta-C D$
}

\author{
Sakthivel Pitchaimuthu $\cdot$ Subramanian Rajalakshmi • \\ Nagarathinam Kannan · Ponnusamy Velusamy
}

Received: 30 May 2013/Accepted: 19 March 2014/Published online: 1 May 2014

(C) The Author(s) 2014. This article is published with open access at Springerlink.com

\begin{abstract}
In the current work, the commercially available $\mathrm{ZnO}$ photocatalyst was used to investigate the photodecoloration of Acid yellow 99 (AY99) dye under solar light radiation. Promising enhancement of photodecoloration of AY99 dye was also achieved by the addition of $\beta$-cyclodextrin $(\beta-\mathrm{CD})$ with the $\mathrm{ZnO}(\mathrm{ZnO}-\beta-\mathrm{CD})$. The effects of process parameters such as initial concentration, $\mathrm{pH}$, catalyst loading, and illumination time on the extent of decoloration were investigated. The optimum catalyst loading was observed at $2.0 \mathrm{~g} / \mathrm{L}$. The higher photoactivity of $\mathrm{ZnO}-$ $\beta$-CD/solar light system than $\mathrm{ZnO} /$ solar light system can be ascribed due to the ligand to metal charge transfer (LMCT) from $\beta-\mathrm{CD}$ to $\mathrm{Zn}{ }^{\mathrm{II}}$. The complexation patterns have been confirmed with UV-visible and FT-IR spectroscopy and the interaction between $\mathrm{ZnO}$ and $\beta$-CD has been characterized by FE-SEM, powder XRD analysis, and UV-visible diffuse reflectance spectroscopy.
\end{abstract}

Keywords Acid Yellow 99 dye $\cdot \beta$-Cyclodextrin $\cdot \mathrm{ZnO}$. Solar photocatalytic decoloration

\section{Introduction}

Synthetic dyestuffs are extensively used in textile, printing industries, paper, and dye houses due to their ease of production, variety of colors, and fastness compared to natural dyes. Many commercially available dyes

S. Pitchaimuthu $\cdot$ S. Rajalakshmi $\cdot$ N. Kannan ·

P. Velusamy $(\square)$

Centre for Research and Post-graduate Studies in Chemistry,

Ayya Nadar Janaki Ammal College (Autonomous),

Sivakasi 626124, India

e-mail: velusamyanjac@rediffmail.com are known and approximately 1 million tons of these dyes are produced annually worldwide. It has been estimated that more than $10 \%$ of the total dyestuff used in dyeing processes is released into the environment (Habibi and Esfahani 2007). Therefore, they are neither readily degraded nor removed by conventional wastewater treatment. Further, their hydrophilicity limits their removal by coagulation/flocculation, which, in any case, produces large amounts of sludge with consequent disposal problems. However, since even low levels are clearly visible and exert a significant environmental impact, it is necessary to develop effective treatment methods (Habibi et al. 2007).

Various methods are available for the treatment of polluted water. Biological treatment is cost-effective and the majority of dyes are only adsorbed on the sludge and are not degraded. Physical methods such as ion exchange, adsorption, air stripping etc., are also ineffective and they simply transfer the pollutants to another phase rather than destroying them (Sauer et al. 2002). Photocatalysis is an alternative or complementary technology for the treatment of polluted water that has been widely reported (Byrne et al. 2002). The application of illuminated semiconductors for the decomposition of organic contaminants in water has been successfully used for a wide variety of compounds. Over the years, a large number of semiconductors have been used as photocatalysts. The most commonly studied photocatalysts are $\mathrm{TiO}_{2}, \mathrm{ZnO}$, and $\mathrm{CdS}$. $\mathrm{ZnO}$ appears to be a suitable alternative to $\mathrm{TiO}_{2}$ since its photodegradation mechanism has been proven to be similar to that of $\mathrm{TiO}_{2}$ (Rao et al. 2009). Recently, various reports have shown that $\mathrm{ZnO}$ is one of the potential photocatalyst materials. For instances, scientists found that $\mathrm{ZnO}$ nanoparticles exhibit higher rate than that of $\mathrm{TiO}_{2}$ nanoparticles (Velmurugan and Swaminathan 2011; Tian et al. 2012). 
$\mathrm{ZnO}$ is a direct wide bandgap $(3.37 \mathrm{eV})$ semiconductor, is deemed to be one of the most important semiconductor photocatalysts because of its high photosensitivity and stability (Li and Wang 2011). However, despite its great potential, the photocatalytic efficiency remains very low because of the fast recombination of the photogenerated electron-hole pairs in the single phase semiconductor (Hoffmann et al. 1995). Moreover, the wide bandgap semiconductors can only be excited by UV light, which occupies $<10 \%$ of the total energy of the solar radiation (Liao et al. 2006). Therefore, the development of visiblelight-driven photocatalysts with high energy transfer efficiency has become one of the most challenging tasks in these days. Therefore, a number of efforts have been attracted to inhibit the recombination of electron-hole pairs and improve charge transport via coupling the wide band gap semiconductor photocatalysts with other materials ( $\mathrm{Li}$ and Wang 2011), such as metal-doped $\mathrm{ZnO}$ composite (Kong et al. 2010; Mohan et al. 2012), polymer modified $\mathrm{ZnO}$ composite (Qiu et al. 2008), carbon nanotube (CNTs) (Saleh et al. 2011) or graphene-ZnO composites ( $\mathrm{Fu}$ et al. 2012; Luo et al. 2012).

$\beta$-Cyclodextrin $(\beta-C D)$ is an another material for enhancing the photocatalytic activity of semiconductor photocatalyst. CD-modified semiconductor nanocomposites have attracted renewed interest since Willner and colleagues observed that $\beta-\mathrm{CD}$ could stabilize $\mathrm{TiO}_{2}$ colloids and facilitate interfacial electron transfer processes (Willner and Eichen 1987). Cyclodextrins (CDs) are nonreducing cyclic maltooligosaccharides produced from starch by cyclodextrin glycosyltransferase and are composed of a hydrophilic outer surface and a hydrophobic inner cavity. CDs can form inclusion complexes with organic pollutants and organic pesticides to reduce the environmental impact of the chemical pollutants (Ishiwata and Kamiya 1999; Lu et al. 2004; Velusamy et al. 2014; Wang et al. 2006; Zhang et al. 2009, 2010, 2011, 2012, 2013). In this study, the activity of $\mathrm{ZnO}$ and the effect of addition of $\beta-\mathrm{CD}$ with $\mathrm{ZnO}$ on photocatalytic decoloration of Acid Yellow 99 (AY99) dye solutions under solar light radiation have been studied and the results are documented.

\section{Materials and methods}

\section{Materials}

The commercial organic dye AY99 $\left(\lambda_{\max }=445 \mathrm{~nm}\right)$ received from Loba Chemie was used as such. The semiconductor photocatalyst $\mathrm{ZnO}$ was purchased from Merck Chemicals. $\mathrm{ZnO}$ had a particle size $0.1-4 \mu \mathrm{m}$ and surface area $5 \mathrm{~m}^{2} / \mathrm{g}$. $\beta$-Cyclodextrin was received from Himedia

Table 1 Physical properties of Acid Yellow 99 dye and $\beta$-cyclodextrin

\begin{tabular}{|c|c|c|}
\hline Name & Acid Yellow 99 dye & $\beta$-Cyclodextrin \\
\hline Molecular formula & $\mathrm{C}_{16} \mathrm{H}_{13} \mathrm{CrN}_{4} \mathrm{NaO}_{8} \mathrm{~S}$ & $\mathrm{C}_{42} \mathrm{H}_{70} \mathrm{O}_{35}$ \\
\hline Molar weight & 496.35 & $1,135.0$ \\
\hline Appearance & Yellow powder & White powder \\
\hline $\mathrm{pH}$ & 5.4 (acidic dye) & - \\
\hline$\lambda_{\max }$ & $445 \mathrm{~nm}$ & - \\
\hline Structure & & \\
\hline
\end{tabular}


chemicals. All other chemicals were of the Analytical grade received from Merck and used without further purification. Double distilled water was used to prepare all the experimental solutions. The physical properties and structures of AY99 dye and $\beta-C D$ are shown in Table 1.

\section{Characterization}

FE-SEM was used to investigate the morphology of the samples $\beta-\mathrm{CD}, \mathrm{ZnO}$, and $\mathrm{ZnO}-\beta-\mathrm{CD}$. FE-SEM images were obtained on a Carl ZEISS ( $\Sigma$ IGMA Series, Germany) microscope taken at an accelerated voltage of $2 \mathrm{kV}$. X-ray diffraction patterns of powder samples were recorded with a high resolution powder X-ray diffractometer model RICH SIERT \& $\mathrm{Co}$ with $\mathrm{Cu}$ as the $\mathrm{X}$-ray source $(\lambda=1.5406 \times$ $10^{-10} \mathrm{~m}$ ). UV-Vis diffuse reflectance spectra were recorded on a Shimadzu 2550 UV-Vis diffuse reflectance spectrophotometer with $\mathrm{BaSO}_{4}$ as the background between 200 and $700 \mathrm{~nm}$. UV-visible spectra were recorded by a UV-visible spectrophotometer (Shimadzu UV-1700) and the scan range was from 400 to $700 \mathrm{~nm}$. FT-IR spectra were recorded using (Shimadzu 8400S) in the region $4,000-400 \mathrm{~cm}^{-1}$ using $\mathrm{KBr}$ pellets.

\section{$\mathrm{ZnO}-\beta-\mathrm{CD}$ preparation for characterisation}

To study the interaction of $\beta$-CD on $\mathrm{ZnO}$ surface, a suspension containing $2.0 \mathrm{~g} / \mathrm{L} \mathrm{ZnO}$ and $10.0 \mathrm{~g} / \mathrm{L} \beta-\mathrm{CD}$ was magnetically stirred for $24 \mathrm{~h}$ and then centrifuged, later the solid phase was collected. After being centrifuged, the solid phase of the suspension was cautiously washed with double distilled water until no $\beta-C D$ was detected in the supernatant liquid by phenolphthalein colorimetry (Zhang et al. 2012). Eventually, the $\mathrm{ZnO}-\beta$-CD sample was dried at $50{ }^{\circ} \mathrm{C}$. The sample prepared in this way was used for FE-SEM, XRD, and UV-DRS analysis. The calculated adsorption capacity of $\beta$-CD onto $\mathrm{ZnO}$ is $1.176 \mu \mathrm{mol} / \mathrm{g}$ as calculated by Langmuir isotherm model.

For studying the inclusion complex between $\beta-\mathrm{CD}$ and AY99 dye, equimolar ratio of solid AY99 dye and $\beta$-CD were dissolved in minimum amount of water was magnetically stirred for $24 \mathrm{~h}$ and then the complex was dried at $50{ }^{\circ} \mathrm{C}$. This complex was characterized by FT-IR spectral analysis.

\section{Photocatalytic decoloration experiment}

In the photodecoloration of AY99 dye under solar light irradiation, sun light is used as an irradiation source. The intensity of sun light on the day of irradiation was measured using Lux meter. Exactly, $50 \mathrm{ml}$ of the reaction solutions was taken in clean wide mouth glass vessels which were kept at a distance of $20 \mathrm{~cm}$ between each. The direct sun light radiation was allowed to fall on the reaction solutions during noon.
The $\mathrm{pH}$ values of dye solutions were adjusted using digital pen $\mathrm{pH}$ meter (Hanna Instruments, Portugal) depending on desired values with $\mathrm{HCl}$ and $\mathrm{NaOH}$ solution as their effect on the adsorption surface properties of $\mathrm{ZnO}$ is negligible. The $\mathrm{pH}$ of the dye solutions was adjusted before irradiation process and it was not controlled during the course of the reaction. Prior to irradiation, $\mathrm{ZnO}$ suspensions were kept in dark for $10 \mathrm{~min}$ to attain adsorption-desorption equilibrium between dye and $\mathrm{ZnO}$ system. The reaction vessels were taken out at different intervals of time and the solutions were centrifuged. The supernatant liquid was collected and labeled for the determination of concentrations for the remained dye by measuring its absorbance (at $\lambda_{\max }=445 \mathrm{~nm}$ ) with visible spectrophotometer (Elico, Model No. SL207). In all the cases, exactly $50 \mathrm{~mL}$ of reactant solution was irradiated with required amount of photocatalysts.

By keeping the concentrations of AY99 dye- $\beta-C D$ as constant with the molar ratio of $1: 1$, the effects of the other experimental parameters on the rate of photocatalytic decoloration of AY99 dye solutions were investigated. The natural $\mathrm{pH}$ of AY99 dye solution was 5.4 and the irradiation time was fixed as $120 \mathrm{~min}$.

\section{Decoloration kinetics}

The photocatalytic decoloration process of AY99 dye tends to follow pseudo-first order kinetics in the presence of catalysts used in this study. The regression curve of natural logarithm of AY99 dye concentration vs. illumination time shows a straight line using the formula,

$\ln \left(C_{\mathrm{o}} / C_{\mathrm{t}}\right)=k t$

where $C_{\mathrm{o}}$ and $C_{\mathrm{t}}$ represent the initial concentration of the corresponding AY99 dye in solution and that of illumination time of $t$, respectively, and $k$ represents the apparent rate constant $\left(\mathrm{min}^{-1}\right)$ (Chun et al. 2001; Zertal et al. 2004; Rao et al. 2009).

\section{Dissociation constant measurements}

The dissociation constant $\left(K_{\mathrm{D}}\right)$ value for the complexation between $\beta-C D$ and AY99 dye can be calculated using the Benesi-Hildebrand equation (Velusamy et al. 1996).

$$
([\mathrm{C}][\mathrm{S}] / \Delta \mathrm{OD})=([\mathrm{C}]+[\mathrm{S}] / \Delta \varepsilon)+\left(K_{\mathrm{D}} / \Delta \varepsilon\right)
$$

where,

$[\mathrm{C}],[\mathrm{S}]$ represent the concentrations of the $\beta-\mathrm{CD}, \mathrm{AY} 99$ dye molecules, respectively, at equilibrium. $\triangle \mathrm{OD}$, the increase in absorption upon addition of $\beta-\mathrm{CD} ; \Delta \varepsilon$, the difference in molar extinction coefficients between the bound and the free AY99 dye; $K_{\mathrm{D}}$, dissociation constant.

$K_{\mathrm{D}}$ can be obtained from the ratio of the intercept $\left(K_{\mathrm{D}} /\right.$ $\Delta \varepsilon)$ and the slope $(1 / \Delta \varepsilon)$ from the linear plot of [C] [S]/ 
$\Delta \mathrm{OD}$ versus $\{[\mathrm{C}]+[\mathrm{S}]\}$. The determined $K_{\mathrm{D}}$ value is $4.8846 \times 10^{-5} \mathrm{M}$.

\section{Results and discussion}

Field emission scanning electron microscopy

Figure 1 depicts FE-SEM micrograph of the bare $\beta-C D$, bare $\mathrm{ZnO}$, and $\mathrm{ZnO}-\beta-\mathrm{CD}$, respectively. Bare $\beta$-CD shows amorphous surface. The surfaces of bare $\mathrm{ZnO}$ and $\mathrm{ZnO}-\beta$ CD exhibit a similar morphology which indicates that the morphology of $\mathrm{ZnO}$ has not been affected by its complexation with $\beta$-CD. However, the external frontier of the $\mathrm{ZnO}-\beta-\mathrm{CD}$ was noticeably different from $\mathrm{ZnO}$. This may due to the aggregation of $\mathrm{ZnO}$ and $\beta-\mathrm{CD}$ particles as the surfaces of the particles are very loose. This kind of surface arrangement can provide a superior adsorption environment and more active site for the photocatalytic reaction.

X-ray powder diffraction analysis

The X-ray powder diffraction patterns of $\beta$-CD, 1:1 physical mixture $\mathrm{ZnO}-\beta-\mathrm{CD}$, and $\mathrm{ZnO}$ are presented in Fig. $2 \mathrm{a}-\mathrm{c}$, respectively. XRD pattern of the sample is summarized in Fig. 2. All the diffraction peaks of samples can be indexed as the wurtzite structured hexagonal $\mathrm{ZnO}$ with lattice (JCPDS, No. 36-1451), which indicated that the sample is pure $\mathrm{ZnO}$. The high intensities of the XRD peaks of the sample suggest that the $\mathrm{ZnO}$ phase used in this work is highly crystalline. Diffraction peaks at $31.73^{\circ}, 34.45^{\circ}, 36.28^{\circ}, 47.51^{\circ}$, and $56.68^{\circ}$ correspond to (100), (002), (101), (102), and (110) planes of $\mathrm{ZnO}$, respectively. Moreover, the addition of $\beta-\mathrm{CD}$ do not cause any shift in peak position of that of $\mathrm{ZnO}$ phase. The results also demonstrated that the $\mathrm{ZnO}$ conserved their wurtzite crystal features. Addition of $\beta-C D$ causes no effect on the crystalline feature of $\mathrm{ZnO}$.

UV-visible diffuse reflectance spectra

The diffuse reflectance spectra of $\mathrm{ZnO}$ and $\mathrm{ZnO}-\beta-\mathrm{CD}$ catalysts are provided in Fig. 3, respectively. As shown in the Fig. 3b, $\mathrm{ZnO}-\beta-\mathrm{CD}$ has slightly higher absorption intensity in the visible region compared to the bare $\mathrm{ZnO}$ (Fig. 3a), this is attributed to charge transfer ligand to metal charge transfer (LMCT) from $\beta-\mathrm{CD}$ to $\mathrm{Zn}^{\mathrm{II}}$.

UV-visible and FT-IR spectral analysis

The molecular structure of $\beta-C D$ allows various guest molecules with suitable dimensions to form host/guest inclusion complexes. In this study, the inclusion complex between $\beta-C D$ and AY99 dye was characterized with
UV-visible spectrum as given in Fig. 4. Figure 4 depicts that the absorbance of inclusion complex increases with increasing the concentration of $\beta-C D$ (Wang et al. 2006).

Though IR measurements are not employed for detecting inclusion compounds (due to the superposition of host and guest bands), in some cases where the substrate has characterstic absorbance in the regions where $\beta-C D$ does not absorb, IR spectrum is useful. From the FT-IR spectra (Fig. 5), it was observed that the peaks corresponding to monosubstituted benzene $\left(1,596,1,544\right.$ and $\left.1,514 \mathrm{~cm}^{-1}\right)$ for the AY99 dye molecule (Fig. 5b) are presented in the 1:1 physical mixture of $\beta$-CD-AY99 dye complex (Fig. 5c), whereas hidden in the $\beta$-CD-AY99 dye 1:1 complex (Fig. 5d). Moreover, it contains all the absorption peaks related to $\beta$-CD (Fig. 5a). It is interesting to note that the spectrum of a physical mixture of $\beta-C D$ and AY99 dye resemble more of the AY99 dye peaks than that of a complex spectrum. It clearly confirms that there is an inclusion of the AY99 dye molecule inside the $\beta$-CD cavity in such a way that, the complexation between the AY99 dye molecule and $\beta$-CD has been proved by the FT-IR spectral data (Fig. 5).

\section{Effect of initial dye concentration}

The photocatalytic decoloration of AY99 dye was carried out at different initial concentrations ranging from $5.04 \times 10^{-5}$ to $30.22 \times 10^{-5} \mathrm{M}$ in $\mathrm{ZnO}$ and $\mathrm{ZnO}-\beta-\mathrm{CD}$ systems. The percentage removal of AY99 dye was decreased with increase in the concentration of dye. Nevertheless, the decoloration efficiency decreases because the photogeneration of holes or hydroxyl radicals on the catalyst surface is reduced (Guettai and Amar 2005). Under these conditions, the active sites of the catalyst are covered by dye molecules and degradation products, which compete with $\mathrm{H}_{2} \mathrm{O}$ and $\mathrm{OH}^{\bullet}$ to be adsorbed on the same sites, resulting in the lower formation of $\mathrm{OH}^{\bullet}$ radicals, the principal oxidant indispensable for high degradation efficiency (Sahel et al. 2007). In addition, the significant amount of light radiation that may be screened by dye molecules should be taken into account, since less photons reach the photocatalyst surface to further generate $\mathrm{OH}^{\bullet}$ (Guettai and Amar 2005; Camarillo and Rincon 2011).

\section{Effect of initial $\mathrm{pH}$}

The solution $\mathrm{pH}$ appears to play an important role in the photocatalytic process of various pollutants (Krishnakumar et al. 2012). The effect of $\mathrm{pH}$ on the photodecoloration of AY99 dye was studied in the $\mathrm{pH}$ range $1-11$. The Zero Point Charge (pzc) for $\mathrm{ZnO}$ is $9.0 \pm 0.3$. $\mathrm{ZnO}$ surface is positively charged below $\mathrm{pH} 9$, whereas it is negatively charged above pH 9 based on their pzc (Bansal and Sud 2011). AY99 is an acidic dye in aqueous solution. 


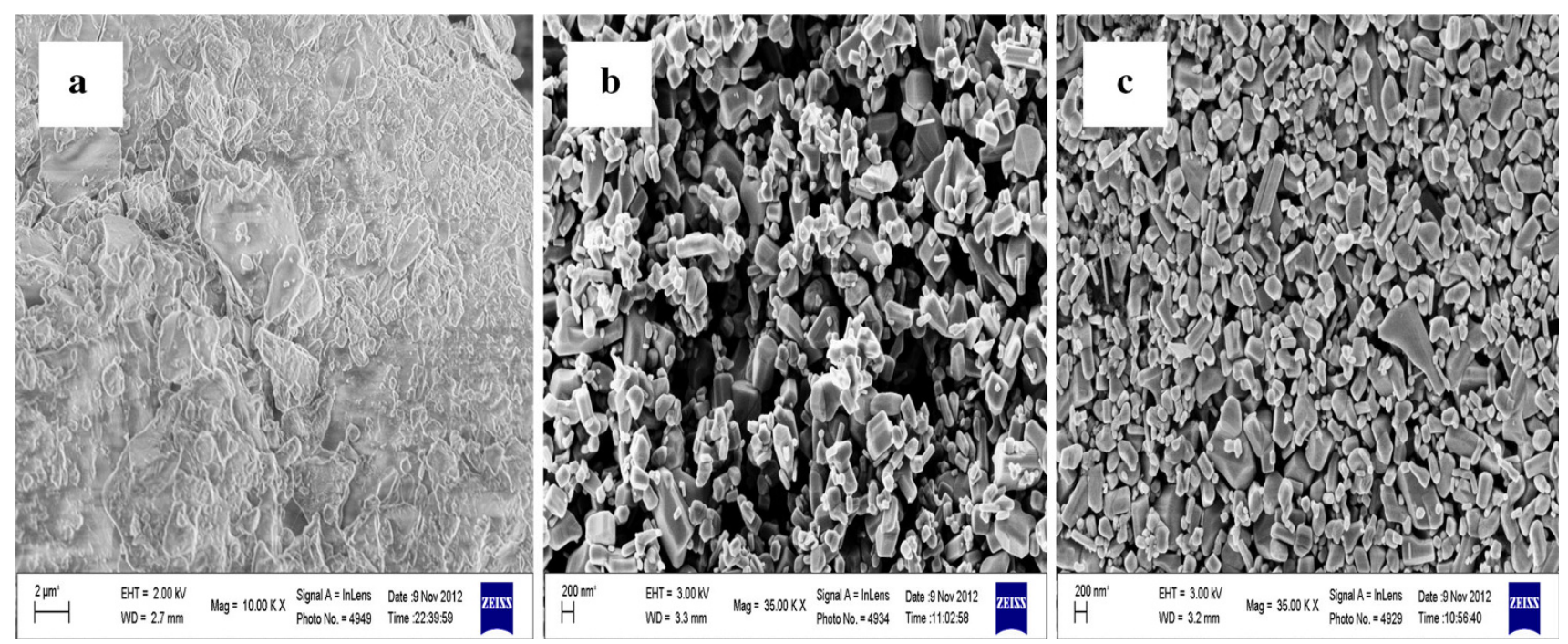

Fig. 1 FE-SEM images of a Bare $\beta$-CD b Bare $\mathrm{ZnO} \mathbf{c} \mathrm{ZnO}-\beta-\mathrm{CD}$

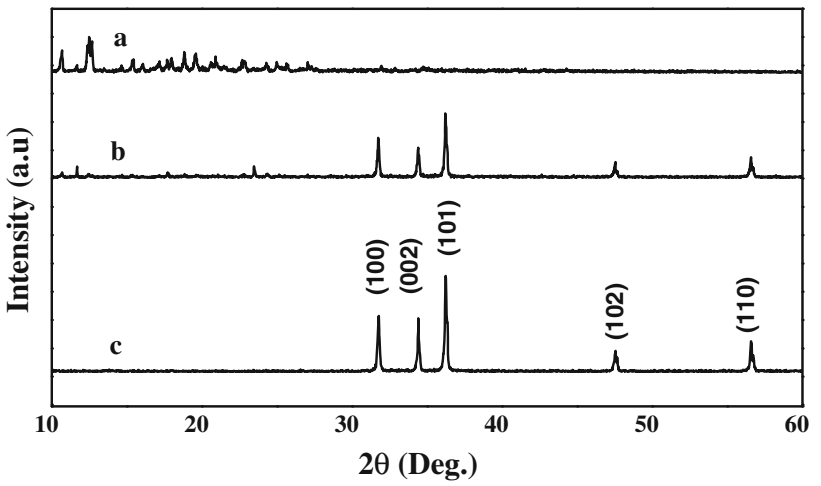

Fig. $2 \mathrm{X}$-ray powder diffraction patterns of $a \beta-\mathrm{CD}, b \mathrm{ZnO}-\beta-\mathrm{CD}, c$ $\mathrm{ZnO}$

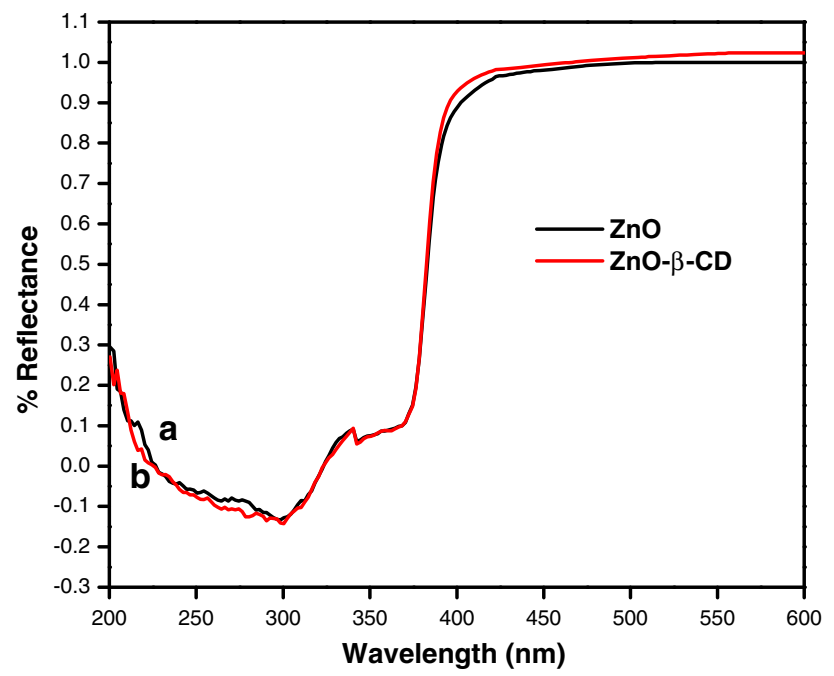

Fig. 3 Diffuse reflectance spectra of $\mathbf{a} \mathrm{ZnO}$ and $\mathbf{b} \mathrm{ZnO}-\beta-\mathrm{CD}$

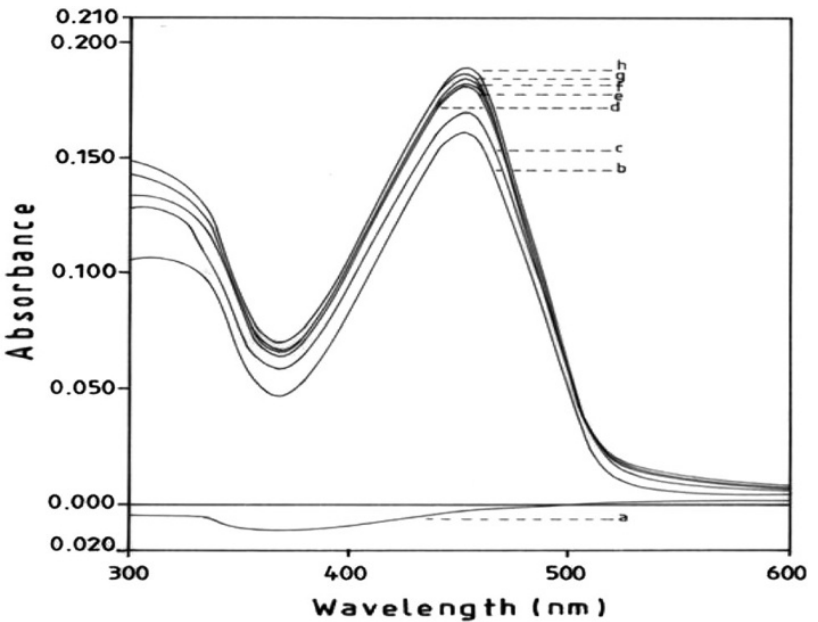

Fig. 4 UV-visible spectral analysis. $a \beta-\mathrm{CD}, b$ AY99 dye, $c$ 1:1

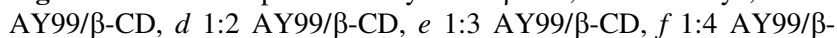
$\mathrm{CD}, g$ 1:5 AY99/ $\beta-\mathrm{CD}, h$ 1:6 AY99/ $\beta-\mathrm{CD}$

At acidic $\mathrm{pH}$ range, the removal efficiency is less and it is due to the dissolution of $\mathrm{ZnO}$. Because $\mathrm{ZnO}$ is amphoteric in nature and is dissolved at lower $\mathrm{pH}$, forming salts. At higher $\mathrm{pH}$, it forms zincates such as $\left[\mathrm{Zn}(\mathrm{OH})_{4}\right]^{2}$. In the basic $\mathrm{pH}, \mathrm{ZnO}$ surface is negatively charged by means of adsorbed $\mathrm{OH}^{-}$ions. The presence of large quantities of $\mathrm{OH}^{-}$ions on the particle surfaces as well as in the reaction medium favors the formation of $\mathrm{OH}^{*}$ (Sobana and Swaminathan 2007). All these factors are responsible for higher decoloration efficiency in basic $\mathrm{pH}$.

Effect of amount of photocatalyst

The influence of the photocatalyst concentration from 0.5 to $3.0 \mathrm{~g} / \mathrm{L}$ for AY99 dye on the photodecoloration 
Fig. 5 FT-IR spectral analysis. $a \beta$-CD, $b$ AY99 dye, $c$ 1:1 physical mixture of $\beta-C D$ and AY99 dye, $d$ 1:1 complex of $\beta$-CD/AY99 dye

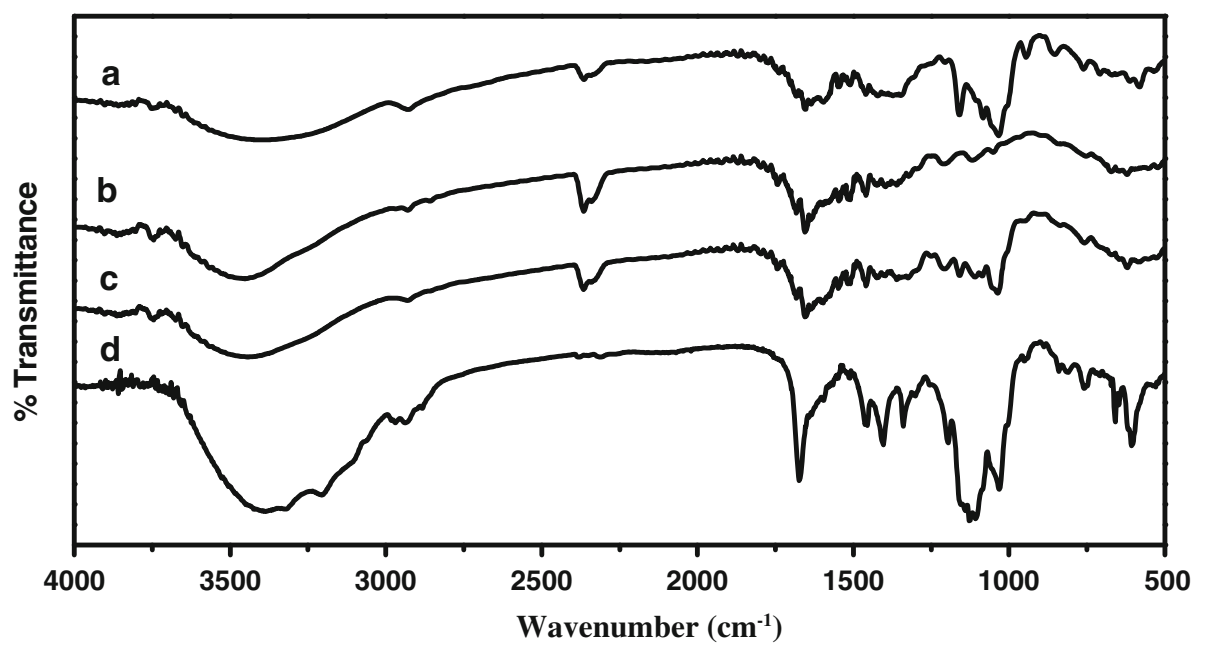

efficiency was investigated. The observed results revealed that the photodecoloration efficiency increases with increase in $\mathrm{ZnO}$ concentration. This can be explained in terms of availability of active sites on the catalyst surface and the penetration of solar light into the suspension. The total active surface area increases with increasing catalyst dosage. Hence, the optimum amount of catalyst for photocatalytic decoloration of AY99 dye was found to be $2.0 \mathrm{~g} / \mathrm{L}$. All the process parameters were performed with this concentration of $\mathrm{ZnO}$.

\section{Effect of illumination time}

Illumination time plays an important role in the decoloration process of the pollutants. The illumination time was varied from 30 to $180 \mathrm{~min}$. The remaining concentration is decreased with an increase in the illumination time. It was observed that nearly $98.0 \%$ decoloration of AY99 dye solution is achieved with in $180 \mathrm{~min}$.

Figure 6 shows the maximum percentage removal of AY99 dye with various operational parameters. It is observed that $\mathrm{ZnO}-\beta-\mathrm{CD} /$ Solar light system exhibits better photocatalytic decoloration efficiency than that of $\mathrm{ZnO} /$ Solar light system.

\section{Mechanism of the effect of $\beta$-CD on photodecoloration}

The proposed mechanism for the photocatalytic decoloration of AY99 dye by excitation of $\mathrm{ZnO} / \beta-\mathrm{CD}$ is shown in Fig. 7. Since $\beta-C D$ has higher affinity on $\mathrm{ZnO}$ surface than dye molecules, $\beta$-CD molecules could be adsorbed on $\mathrm{ZnO}$ surface and engage the active sites. $\beta-\mathrm{CD}$ would capture holes on active $\mathrm{ZnO}$ surface resulting in the formation of stable $\mathrm{ZnO} / \beta-\mathrm{CD}$ inclusion complex. So, the inclusion complex reaction of $\beta-C D$ with dye molecules should be the key step in photocatalytic decoloration in $\mathrm{ZnO}$ suspension containing $\beta$-CD. Dye molecules form inclusion

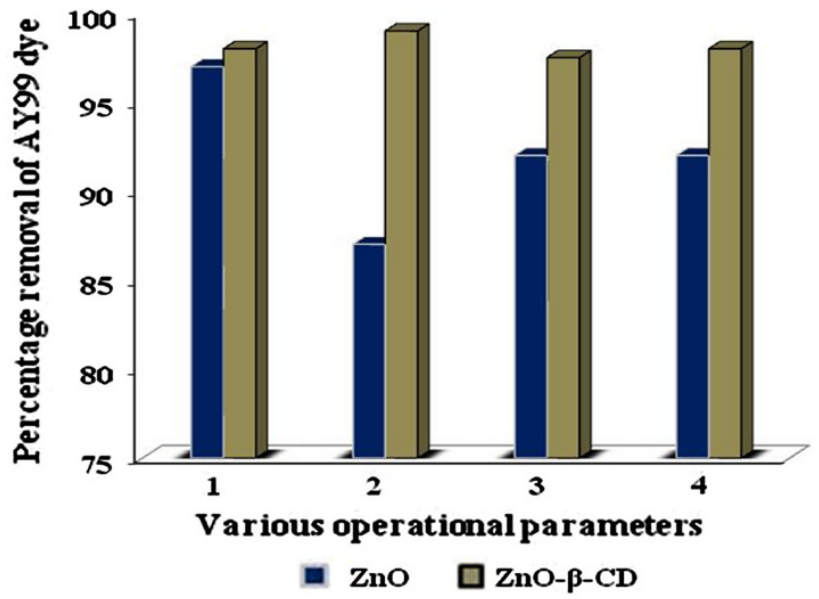

Fig. 6 Effect of various operational parameters on decoloration of AY99 dye. Where, 1 effect of initial concentration of AY99 dye solutions; 2 effect of $\mathrm{pH}$ variation; 3 effect of dose variation; 4 effect of irradiation time

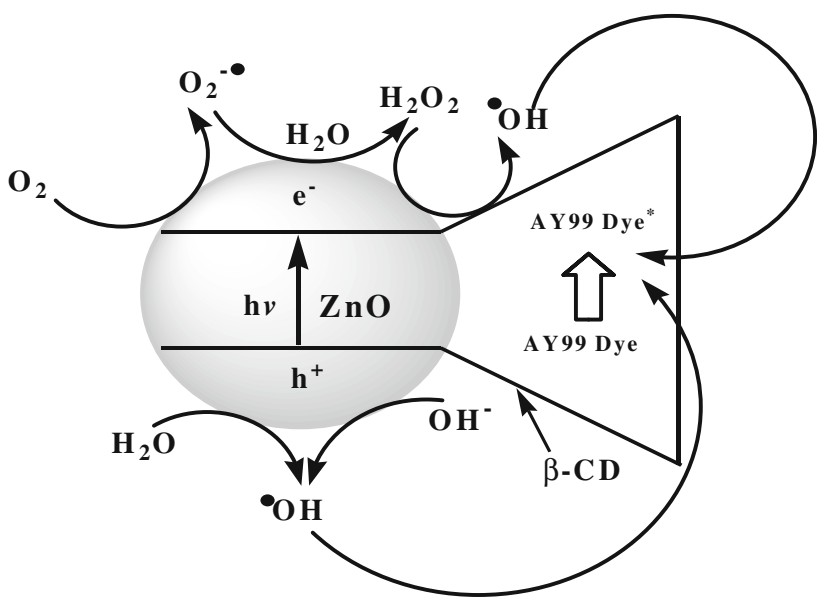

Fig. 7 Proposed mechanism for the photodecoloration of AY99 dye with $\mathrm{ZnO}-\beta-\mathrm{CD}$ 
complex resulting in the indirect photodecoloration to be the main reaction channel (Zhang et al. 2009). AY99 dye molecules enter into the cavity of $\beta-\mathrm{CD}$, which is linked to the $\mathrm{ZnO}$ surface in the equilibrium stage and they absorb light radiation followed by excitation. An electron is rapidly injected from the excited dye to the conduction band of $\mathrm{ZnO}$. Another important radical in illumination of $\mathrm{ZnO}-$ $\beta$-CD is the superoxide anion radical $\left(\bullet \mathrm{O}^{2-}\right)$. The dye and dye cation radical then undergo degradation.

$\beta-\mathrm{CD} / \mathrm{ZnO}$ could show significant photocatalytic activity mainly because $\beta-C D$ could trap the photo generated holes resulting in the lower $e_{\mathrm{CB}}^{-} / h_{\mathrm{VB}}^{+}$recombination (Zhang et al. 2010). In general, the lifetimes for the excited states of unreacted guests are prolonged when incorporated inside the cavity of CDs. Therefore, cyclodextrin facilitates the electron injection from the excited dyes to the $\mathrm{ZnO}$ conduction band and thereby enhances the decoloration (Zhang et al. 2011).

\section{Conclusion}

In this work, we carried out a detailed study of the effect of $\beta-\mathrm{CD}$ on the photodegradation of AY99 dye in $\mathrm{ZnO}$ suspension. XRD analysis exposes that $\mathrm{ZnO}$ conserved their wurtzite crystal features during the irradiation. Addition of $\beta$-CD does not cause any shift in peak position of that of $\mathrm{ZnO}$ phase. The results also demonstrated that the wurtzite $\mathrm{ZnO}$ conserved their wurtzite crystal features. UV-visible diffuse reflectance spectra exhibit that $\beta$-CD addition leads to a significant effect on the optical characteristics of $\mathrm{ZnO}$. $\mathrm{ZnO}-\beta-\mathrm{CD}$ system has faintly superior absorption intensity in the visible region compared to the bare $\mathrm{ZnO}$ system. Hence, photodecoloration of AY99 dye in $\mathrm{ZnO}-\beta-\mathrm{CD} /$ solar light system exhibits better photocatalytic decoloration efficiency than that of $\mathrm{ZnO} /$ solar light system. This work provides essential information on the promotion effects of $\beta$-CD on the photodegradability of $\mathrm{ZnO}$ on dye in aqueous solution.

Acknowledgments The authors thank the Management and the Principal of Ayya Nadar Janaki Ammal College, Sivakasi, India for providing necessary facilities. Authors also thank the University Grants Commission, New Delhi, for the financial support through UGC-Major Research Project Ref. [UGC-Ref. No.F. No. 38-22/ 2009 (SR) Dated: 19.12.2009]. The instrumentation centre, Ayya Nadar Janaki Ammal College, Sivakasi and Department of Earthscience, Pondicherry University, Pondicherry are highly appreciated for recording the UV-visible, FT-IR spectra and Powder XRD patterns, respectively.

Open Access This article is distributed under the terms of the Creative Commons Attribution License which permits any use, distribution, and reproduction in any medium, provided the original author(s) and the source are credited.

\section{References}

Bansal P, Sud D (2011) Photodegradation of commercial dye, Procion Blue HERD from real textile wastewater using nanocatalysts. Desalination 267(2-3):244-249

Byrne JA, Davidson A, Dunlop PSM, Eggins BR (2002) Water treatment using nano-crystalline $\mathrm{TiO}_{2}$ electrodes. J Photochem Photobiol A 148(1-3):365-374

Camarillo R, Rincon J (2011) Photocatalytic discoloration of dyes: relation between effect of operating parameters and dye structure. Chem Eng Technol 34(10):1675-1684

Chun H, Yizhong W, Hongxiao T (2001) Preparation and characterization of surface bond-conjugated $\mathrm{TiO}_{2} / \mathrm{SiO}_{2}$ and photocatalysis for azo dyes. Appl Catal B 30(3-4):277-285

Fu D, Han G, Chang Y, Dong J (2012) The synthesis and properties of $\mathrm{ZnO}-$ graphene nano hybrid for photodegradation of organic pollutant in water. Mater Chem Phys 132(2-3):673-681

Guettai N, Amar HA (2005) Photocatalytic oxidation of methyl orange in presence of titanium dioxide in aqueous suspension. Part I: parametric study. Desalination 185(1-3):427-437

Habibi MH, Esfahani MN (2007) Preparation, characterization and photocatalytic activity of a novel nanostructure composite film derived from nanopowder $\mathrm{TiO}_{2}$ and sol-gel process using organic dispersant. Dyes Pigment 75(3):714-722

Habibi MH, Esfahani MN, Egerton TA (2007) Preparation, characterization and photocatalytic activity of $\mathrm{TiO}_{2} /$ methylcellulose nanocomposite films derived from nanopowder $\mathrm{TiO}_{2}$ and modified sol-gel titania. J Mater Sci 42(15):6027-6035

Hoffmann MR, Martin ST, Choi W, Bahnemann DW (1995) Environmental applications of semiconductor photocatalysis. Chem Rev 95(1):69-96

Ishiwata S, Kamiya M (1999) Effects of humic acids on the inclusion complexation of cyclodextrins with organophosphorous pesticides. Chemosphere 38(10):2219-2226

Kong JZ, Li AD, Li XY, Zhai HF, Zhang WQ, Gong YP, Li H, Wu D (2010) Photo-degradation of methylene blue using Ta-doped $\mathrm{ZnO}$ nanoparticle. J Solid State Chem 183(6):1359-1364

Krishnakumar B, Subash B, Swaminathan M (2012) AgBr-ZnO-an efficient nano-photocatalyst for the mineralization of Acid Black 1 with UV light. Sep Purif Technol 85:35-44

Li B, Wang Y (2011) Synthesis, microstructure, and photocatalysis of $\mathrm{ZnO} /$ CdS nano-heterostructure. J Phys Chem Solids 72(10):1165-1169

Liao SC, Lin HF, Hung SW, Hu CT (2006) dc thermal plasma synthesis and properties of zinc oxide nanorods. J Vac Sci Technol B 24(3):1322-1326

Lu P, Wu F, Deng N (2004) Enhancement of $\mathrm{TiO}_{2}$ photocatalytic redox ability by $\beta$-cyclodextrin in suspended solutions. Appl Catal B 53(2):87-93

Luo QP, Yu X, Lei BX, Chen HY, Kuang DB, Su CY (2012) Reduced graphene oxide hierarchical $\mathrm{ZnO}$ hollow sphere composites with enhanced photocurrent and photocatalytic activity. J Phys Chem C 116(14):8111-8117

Mohan R, Krishnamoorthy K, Kim SJ (2012) Enhanced photocatalytic activity of $\mathrm{Cu}$-doped $\mathrm{ZnO}$ nanorods. Solid State Commun 152(5):375-380

Qiu R, Zhang D, Mo Y, Song L, Brewer E, Huang X, Xiong Y (2008) Photocatalytic activity of polymer-modified $\mathrm{ZnO}$ under visible light irradiation. J Hazard Mater 156(1-3):80-85

Rao AN, Sivasankar B, Sadasivam V (2009) Kinetic study on the photocatalytic degradation of salicylic acid using $\mathrm{ZnO}$ catalyst. J Hazard Mater 166(2-3):1357-1361

Sahel K, Perol N, Chermette H, Bordes C, Derriche Z, Guillard C (2007) Photocatalytic decolorization of Remazol Black 5 (RB5) and Procion Red MX-5B-Isotherm of adsorption, kinetic of

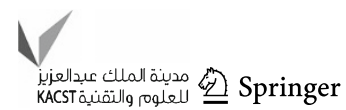


decolorization and mineralization. Appl Catal B 77(1-2): 100-109

Saleh TA, Gondal MA, Drmosh QA, Yamani ZH, AL-yamani A (2011) Enhancement in photocatalytic activity for acetaldehyde removal by embedding $\mathrm{ZnO}$ nano particles on multiwall carbon nanotubes. Chem Eng J 166(1):407-412

Sauer T, Neto GC, Jose HJ, Moreira RFPM (2002) Kinetics of photocatalytic degradation of reactive dyes in a $\mathrm{TiO}_{2}$ slurry reactor. J Photochem Photobiol A 149(1-3):147-154

Sobana N, Swaminathan M (2007) The effect of operational parameters on the photocatalytic degradation of acid red 18 by ZnO. Sep Purif Technol 56(1):101-107

Tian C, Zhang Q, Wu A, Jiang M, Liang Z, Jiang B, Fu H (2012) Cost-effective large-scale synthesis of $\mathrm{ZnO}$ photocatalyst with excellent performance for dye photodegradation. Chem Commun 48(23):2858-2860

Velmurugan R, Swaminathan M (2011) An efficient nanostructured $\mathrm{ZnO}$ for dye sensitized degradation of Reactive Red 120 dye under solar light. Sol Ener Mater Sol Cells 95(3):942-950

Velusamy P, Pitchumani K, Srinivasan C (1996) Selectivity in the bromination of aniline and $\mathrm{N}$-substituted anilines encapsulated in $\beta$-cyclodextrin. Tetrahedron 52(10):3487-3496

Velusamy P, Pitchaimuthu S, Rajalakshmi S, Kannan N (2014) Modification of the photocatalytic activity of $\mathrm{TiO}_{2}$ by $\beta$ cyclodextrin in decoloration of ethyl violet dye. J Adv Res 5(1):19-25

Wang G, Wu F, Zhang X, Luo M, Deng N (2006) Enhanced $\mathrm{TiO}_{2}$ photocatalytic degradation of bisphenol A by $\beta$-cyclodextrin in suspended solutions. J Photochem Photobiol A 179(1-2):49-56
Willner I, Eichen Y (1987) $\mathrm{TiO}_{2}$ and CdS colloids stabilized by $\beta$ cyclodextrins: tailored semiconductor-receptor systems as a means to control interfacial electron-transfer processes. J Am Chem Soc 109:6863-6865

Zertal A, Gabor DM, Malouki MA, Sehili T, Boule P (2004) Photocatalytic transformation of4-chloro-2-methylphenoxyacetic acid (MCPA) on several kinds of $\mathrm{TiO}_{2}$. Appl Catal B 49(2):83-89

Zhang X, Wu F, Wang Z, Guo Y, Deng N (2009) Photocatalytic degradation of 4,4-biphenol in $\mathrm{TiO}_{2}$ suspension in the presence of cyclodextrins: a trinity integrated mechanism. J Mol Catal A 301(1-2):134-139

Zhang X, Wu F, Deng N (2010) Degradation of paracetamol in self assembly $\beta$-cyclodextrin/ $/ \mathrm{TiO}_{2}$ suspension under visible irradiation. Catal Commun 11:422-425

Zhang X, Wu F, Deng N (2011) Efficient photodegradation of dyes using light-induced self assembly $\mathrm{TiO}_{2} / \beta$-cyclodextrin hybrid nanoparticles under visible light irradiation. J Hazard Mater $185: 117-123$

Zhang X, Li X, Deng N (2012) Enhanced and selective degradation of pollutants over cyclodextrin/ $/ \mathrm{TiO}_{2}$ under visible light irradiation. Ind Eng Chem Res 51:704-709

Zhang X, Yang Z, Li X, Deng N, Qiana S (2013) $\beta$-Cyclodextrin's orientation onto $\mathrm{TiO}_{2}$ and its paradoxical role in guest's photodegradation. Chem Commun 49(8):825-827 